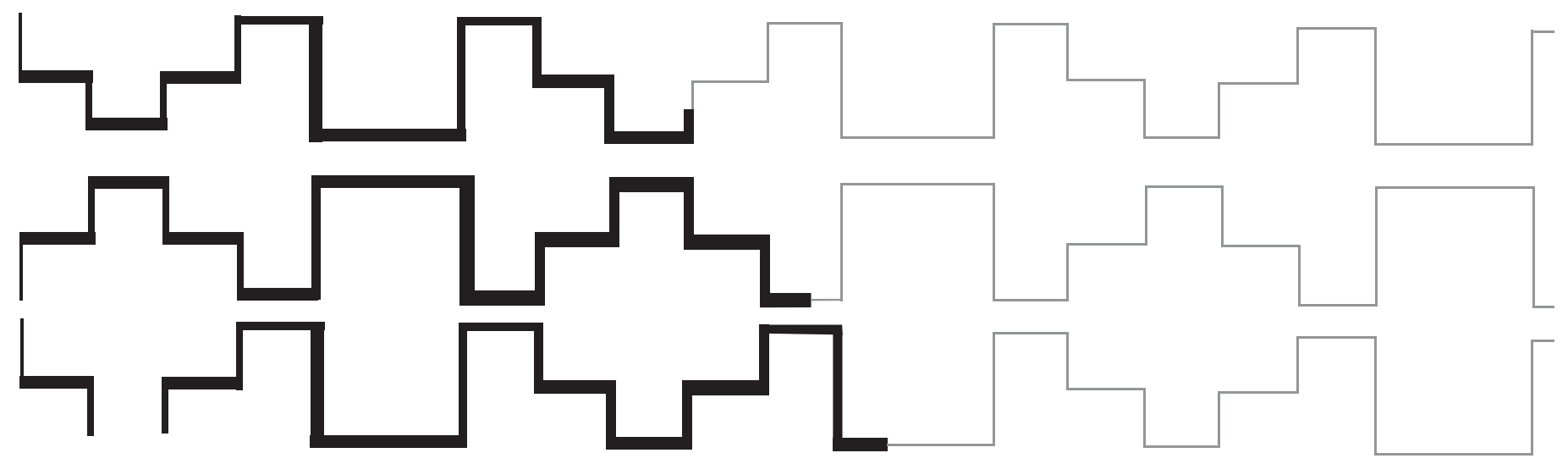

\title{
A cidade arltiana: diálogos com o expressionismo alemão
}

\author{
Janete Elenice Jorge
}

\section{Resumo}

A proposta deste trabalho é observar como foi construída a Buenos Aires ficcional de Roberto Arlt no texto Los siete locos e Los lanzallamas e, através das características da cidade que emerge da narrativa, verificar de que maneira o texto arltiano dialoga com o expressionismo alemão. Serão capturados alguns traços característicos do expressionismo, em especial da pintura expressionista, para reconhecê-los na escritura arltiana. Acredito que o espaço nos romances de Arlt, relacionado à modernidade e à urbanização como fator negativo, também pode ser encontrado no expressionismo alemão numa releitura que coloca em diálogo as inquietações de alguns artistas alemães com as do escritor argentino.

Palavras-chaves: Roberto Arlt; cidade; Expressionismo alemão.

\begin{abstract}
The objective of this paper is to observe how Roberto Arlt's ficcional Buenos Aires was built in the text Los Siete Locos and Los Lanzallamas, and through the characteristics of the city which emerges from the narrative, check in what way the text of Arlt has a dialogue with the German expressionism. Some characterisc traces of the expressionism will be captured, in special in expressionist painting, to recognize them in Arlt's writing. I believe that the space in Arlt's romancess, related to modernity and urbanization as a negative factor, can also be found in the German expressionism in a re-reading which puts in a dialogue
\end{abstract}


the concerns of some German artists together with those of the Argentinian writer.

Keywords: Robert Arlt; city; German expressionism

Para verificar como a cidade arltiana nos textos Los siete locos e Los lanzallamas de Roberto Arlt dialogam com o expressionismo, pretende-se, neste artigo, capturar alguns traços característicos do expressionismo, em especial da pintura expressionista, e reconhecê-los na escritura arltiana. É importante ressaltar que para situar esta investigação com relação à tendência expressionista no texto de Roberto Arlt, deve-se ter claro o conceito de expressionismo que, nesse caso, concorda com a leitura de Maryse Renaud (2000), em seu texto Los siete locos y Los lanzallamas: audácia y candor del expresionismo.

A autora comenta sobre a definição de expressionismo que deverá guiar nossa leitura com relação ao texto arltiano, onde esta não será a de um expressionismo literário internacional alheio às fronteiras e épocas. Não esta constante da literatura universal e sua atitude estética característica da geração de escritores que publicam entre 1915 e 1935, e sim as vertentes que dizem respeito à angústia, ao grito e à impotência do homem frente à barbárie ao seu redor. Renaud postula a existência de uma filiação estética mais direta entre a escrita arltiana e o movimento expressionista alemão propriamente dito dos primeiros decênios de nosso século.

A leitura do texto arltiano, através de um olhar para o expressionismo, será guiada pela análise da cidade ficcional construída pelo escritor e da relação dessa urbe e dos protagonistas com a modernidade. Assim como os artistas Ludwig Meidner e George Grosz, Arlt também retratou as aceleradas transformações que modificaram a paisagem urbana, caricaturou e satirizou os tipos sociais, percebeu a modernização através de um mundo decadente e caótico. E também, como os artistas expressionistas, pode-se supor que Roberto Arlt estava mais interessado na interiorização da criação artística do que em sua exteriorização, projetando em seus textos uma reflexão individual e subjetiva.

Em alguns estudos encontramos, como denominação de arte expressionista, a arte alemã do início do século XX, entretanto, o Expressionismo pode ser considerado um fenômeno europeu de duas vertentes distintas: os fauves (feras) na França e o Die Brücke (A Ponte) na Alemanha. Os dois movimentos surgem em 1905 e culminarão, respectivamente, no Cubismo, na França em 1908, e na corrente Der Blaue Reiter (O Cavaleiro Azul), na Alemanha em 1911.

O grupo dos fauves não apresentava homogeneidade: tinha Matisse como personalidade de destaque, se opunha ao decorativismo hedonista do Art Nouveau, à inconsistência formal, à evasão espiritualista do simbolismo e não sustentava nenhuma bandeira ideológica, pois sua polêmica social encontrava-se implícita em sua poética.

Segundo Giulio Carlo Argan (1998, p. 232) os fauves pretendiam dar destaque à estrutura autossuficiente do quadro, como realidade em si, do mesmo modo que André Gide, conhecido como o equivalente literário de Matisse, considerava a obra literária como um sistema autônomo fechado, cuja lei estrutural não consiste na verossimilhança dos eventos narrados, nem na coerência psicológica dos personagens.

O grupo Die Brücke apresentava uma formação mais compacta e tinha um programa definido. Seus principais representantes eram: Ernst Ludwig Kirchner, Erich Heckel, Emil Nolde, Karl Schmidt-Rottluff, Otto Muller e o escultor Ernst Barlach. No 
ano 1910 a arte dos Brücke alcança maturidade, seu universo temático discorre sobre o rural e o urbano e os temas da natureza e da modernidade serão bastante explorados. Entre 1901 e 1911 os artistas do Die Brücke parecem não ampliar as tensões entre a cidade e o campo, a tendência é naturalizar as experiências do ambiente urbano que, de certo modo, exercia atração nos artistas.

As periferias de Dresden ganham expressividade nas telas dos artistas do Die Brücke. Segundo Shulamith Behr naquela época já eram comuns os sanatórios e as clínicas de repouso prosperavam, o centro de banhos ao ar livre e a cultura do corpo eram práticas constantes, o que proporcionava aos artistas desenvolver nesse ambiente seus ideais de liberdade sexual e estilo antiburguês de vida. Behr ainda aponta que

A teoria baudelairiana da modernidade, a qual exige do artista ser uma pessoa de seu tempo, foi evidentemente abraçada com fervor, à medida que Kirchner estabeleceu, sem rodeios, a associação dos Brücke com o mundo das dançarinas, prostitutas e performistas, que muitas vezes serviam de objeto para os trabalhos do grupo. (1998, p. 28)

Assim como Kirchner, através de uma abordagem distinta, Roberto Arlt também deixou transparecer sem rodeios em suas obras as periferias e o submundo da prostituição. Tanto Arlt como grande parte dos artistas expressionistas trabalharam com a expressão de lugares não legitimados. É em Berlim que os artistas do Die Brücke experimentam intensamente as transformações da modernidade e modificam sua interpretação sobre a vida urbana. Proliferavam na imprensa as críticas à metrópole e à modernização, e Berlim não era somente palco dos críticos como também a cidade alvo das críticas.

O processo de modernização de Berlim dá-se entre 1871, na unificação da Alemanha, e a Primeira Guerra Mundial, em 1914. A cidade, durante esse período, sofre profundas mudanças, reflexo do poder econômico e militar prussiano. A paisagem da cidade irá sofrer alterações constantes e radicais, na medida em que as fábricas e estações de trem vão sendo arquitetadas em sintonia com outras novas construções. A modernidade em Berlim, assim como na Buenos Aires das primeiras décadas do século XX, vem acompanhada do impacto negativo da urbanização.

Conforme dados históricos sobre Berlim, recolhidos por Shulamith Behr "entre 1800 e 1900, a população da cidade havia aumentado de 170.000 pessoas para quase dois milhões, em consequência da chegada contínua de imigrantes, a maioria proveniente das áreas rurais da Prússia Oriental” (2000, p. 47). A imigração acelerada e desordenada irá provocar radicais transformações demográficas. Assim como na Buenos Aires imigratória, proliferarão em Berlim os distritos operários, os subúrbios abarrotados, contrastando com as áreas nobres em crescente expansão, incorporando, assim, os conflitos e as contradições da modernidade.

O artista expressionista George Grosz descreve bem as periferias da Berlim em vias de modernização: "as periferias da cidade, que se expandia como um polvo (...) aquelas bizarras paisagens urbanas, nas quais trens bafejavam sobre pontes, montes de lixo atulhavam terrenos demarcados, e misturadores de concreto estavam prontos para novas ruas abertas" (BEHR, 2000, p. 48). Berlim, assim descrita por Grosz, recorda a Buenos Aires arltiana percorrida por Erdosain em Los siete locos e Los lanzallamas. A 
modernidade caótica e infernal dialogando com o expressionismo alemão, em especial o dos Brücke, irá desenhar metrópoles semelhantes tanto na pintura quanto na literatura.

O expressionismo a partir de Berlim irá elaborar uma nova mitologia da cidade e é nesse momento que as ruas e as aglomerações da metrópole serão retratadas com a intensidade que lhes é própria. Ernst Ludwig Kirchner, George Grosz e Ludwig Meidner irão registrar a experiência urbana na cidade moderna de maneira que nos é possível estabelecer algumas relações com a cidade ficcional que emerge da prosa arltiana.

George Grosz foi um expressionista que se propôs a retratar o submundo da cidade moderna. O artista era membro da corrente expressionista Neue Sacblichkeit, formada após a dissolução do Die Brücke em 1913. Grosz trabalhava com temas baseados na vida na metrópole e entre eles encontravam-se o suicídio, as fantasias eróticas e cenas de assassinato, de estupro e de insanidade que, depois da guerra, passam a ser retratadas com alto teor de violência e pessimismo.

Essa temática, nas obras do artista, perdeu "seus sobretons fin-de-siècle quando Grosz engajou-se na distorção expressionista, além de sofrerem dramáticas mudanças na escala e na intensidade da coloração utilizada na interpretação da paisagem urbana" (BEHR, 2000, p. 61). No ano de 1918, Grosz associa-se ao Dadaísmo que chega a Zurique em 1916, em seguida em Berlim, proliferando-se a outras cidades da Alemanha.

Shulamith Behr comenta que essas características são evidentes na tela Suicídio, pintada por Grosz em 1916. O quadro retrata um quarteirão de um bairro de prostituição, onde a futilidade da existência é encenada.

\begin{abstract}
Um suicida está pendurado num poste e, estendida no primeiro plano, a figura de uma provável vítima de assassinato. Seus corpos sem vida contrastam com o tom vivo do vermelho que domina a superfície, iluminando os cachorros e um suspeito do assassinato ou possível ladrão que se esgueira. A pintura também contém um interior doméstico e vulgar, que exibe o objeto de desejos não satisfeitos - a prostituta parcialmente coberta emoldurada por uma janela. (BEHR, 2000, p. 61)
\end{abstract}

O suicídio também é explorado por Arlt. O protagonista do díptico arltiano, ao final do romance, comete suicídio dentro de um trem. Depois de muito deambular pela cidade, Erdosain atira no próprio peito na tentativa de evadir-se dos problemas e misérias de sua existência, assim como para o indivíduo da cidade moderna descrito por Simmel (1979) "era-lhe impossível manter sua individualidade perante as impressionantes forças impessoais que pairavam na cidade moderna". A tecnificação da vida tornou-se insuportável, o personagem se negava adaptar-se aos grandes aglomerados humanos no anseio de ver desaparecer suas características pessoais. Sentindo-se impotente e esmagado pelos mecanismos da metrópole, Erdosain, assim como o suicida da tela de Grosz, comete suicídio em um lugar público, como quem não quisesse esconder dos transeuntes da cidade o imenso tormento que pesava sobre sua vida, finalmente é cessada sua angústia.

A cidade moderna de George Grosz pode ser interpretada como o interior de um organismo vivo, um ser que "engole" os indivíduos. No quadro Grobsstadt (A 
cidade) de 1916, observa-se uma massa humana no interior de uma paisagem urbana onde as imagens das pessoas parecem fundir-se com a topografia da cidade. A predominância da cor vermelha na paisagem dá a impressão de que as figuras estão envoltas por uma massa sanguinolenta. A falta de espaço instala uma continuidade tátil, onde tudo se toca, perde-se a transparência, tudo está imerso em um obsceno e mórbido vermelho.

A cidade arltiana também se assemelha a um organismo vivo, ao qual a linguagem dá forma e conteúdo; as ruas da Buenos Aires ficcional de Arlt se alastram como tentáculos de um imenso polvo. Ezequiel Martínez Estrada descreveu a Buenos Aires dos anos 30 da seguinte maneira:

Buenos Aires era um monstro macrocefálico que gerava uma vida próxima à miséria, condição originada em sua impiedosa "inurbanidade". Da cabeça de seu gigante Golias saíam também oito tentáculos, que se correspondiam perfeitamente com outros tantos terminais de estações de trem. Certamente aquele animal configurava-se bastante mais abominável: as pontas dos tentáculos tinham bocas que tragavam e cuspiam pessoas. (BRESCIANI, 2001, p. 47)

A metáfora biológica da cidade também pode ser aplicada a Buenos Aires ficcional de Arlt, essa cidade devoradora que se alimenta de concreto, tecnologia e massa humana, expandindo seus limites, parasitando as áreas ao seu redor, drenando recursos, brutalizando ambientes e pessoas.

A cidade de Grosz em alguns momentos também poderá ser lida como um grande prostíbulo que atrai os sujeitos pela promessa de felicidade sexual que nunca se realizará. Na tela Metropolis (Metrópole), de 1917, Grosz retrata o ambiente noturno de uma cidade novamente vermelha, onde figuras masculinas caminham em meio às prostitutas. Na cidade arltiana a prostituição desempenha importante papel; pervertidas as relações matrimoniais, o marido procura com a prostituta a felicidade sexual e Arlt sustenta a ideia de que o matrimônio e a prostituição correspondem ao mesmo princípio.

A presença do Lustmord (crimes passionais) também é recorrente nas obras de Grosz e Arlt. A violência contra as figuras femininas, em ambos os casos, aparece através da intensidade das manchas vermelhas de sangue, da presença da cor azulada no corpo que ressalta o estado moribundo e da expressão no rosto da vítima. É possível observar essas características na passagem de Los lanzallamas, na qual Erdosain assassina a Bizca, e na tela de Grosz, intitulada Jobn, der Frauenmörder (João, a esposa do assassino), onde o ambiente das duas "cenas" é o interior de um quarto decadente e neles um corpo nu feminino estirado na cama constitui o foco da violência.

Outro artista investigado que podemos estabelecer relações entre sua obra e a cidade arltiana é o pintor e artista gráfico Ludwig Meidner, que era membro do grupo expressionista Die Pathetiker (Os Patéticos). Meidner estudou arte em Breslau, em 1905 mudou-se para Berlim, em seguida para Paris onde ficou até 1907, experiência que lhe aprimorou o contato com a vida urbana. Entretanto, em suas telas, Meidner não escondia sua preferência por Berlim e, em 1907, quanto volta a esta cidade, passa a se interessar pelos temas da modernidade. Várias telas pintadas por Meidner, entre 1912 e 1916, apresentam um ambiente urbano apocalíptico. A crítica normalmente define esses trabalhos como presságios da destruição causada pela Primeira Guerra Mundial 
em 1914, entretanto, na exposição de 1912, apenas um quadro do catálogo foi definido dessa maneira.

Vários trabalhos de Meidner, pintados anos antes da primeira guerra, apresentam a paisagem urbana destruída, com casas em ruínas, prédios derretidos e pessoas fugindo desesperadas, como se a cidade estivesse se dissolvendo numa explosão cósmica, como se pode observar na tela pintada pelo artista em 1913, intitulada Apokalyptische Landschaft, (Paisagem Apocalíptica). Isso sugere que a obra de Meidner "nasceu de um conflito entre seus pressupostos utópicos e a modernização do mundo, que era visto como em decadência, caótico e arruinado." (BERH, 2000, p. 55)

Dentre os artistas expressionistas investigados nesta pesquisa, acredita-se que a paisagem urbana de Meidner é a que apresente maiores pontos de contato com a cidade ficcional construída na literatura de Roberto Arlt. A ideia de cidade apocalíptica, lugar da negatividade e da dilaceração, onde os indivíduos vivem sua angústia, perpassa a obra dos dois artistas. Através de uma visão trágica da vida urbana, Arlt e Meidner retratam os indivíduos em um ambiente de concreto em situações de extremo desamparo, onde as paisagens urbanas são supervalorizadas com a finalidade de apreender os estados da alma através dos espaços exteriores. A relação dos corpos com a paisagem em que estão imersos, em alguns momentos, denota a busca de certa unidade perdida ou impossibilidade desse encontro, além da natureza opressora do mundo ao qual sucumbem.

Em seu autorretrato Ich und Die Stadt (Eu e a cidade), a face ansiosa de Meidner aparece rodeada por uma cidade de concreto - a angulosidade das construções e o caos urbano foram capturados pela tela. "Mais que retratar a alienação na metrópole, $\mathrm{o}$ artista fez seus poderes criativos atuarem em paralelo com o caos, o dinamismo e o tumulto da vida contemporânea." (BEHR, 2000, p. 54)

A mesma angústia desesperadora que se expressa na face da figura em primeiro plano do quadro de Meidner assola Erdosain. Também é possível supor que a origem da tormenta parece a mesma para ambos os casos, é evidente a sensação de angústia, medo, indiferença e pânico que a metrópole provoca nos indivíduos. Erdosain temia pelo destino que lhe aguardava na cidade, estava condenado a caminhar entre as multidões de homens que, como ele, padeciam de uma incessante angústia.

Giulio Carlo Argan, para explicar a relação da arte com a técnica, ou seja, com o trabalho, utiliza como exemplo a xilogravura, onde a imagem é produzida através de operações manuais que implicam atos de violência sobre a matéria que, nesse caso, constitui-se da madeira. Segunda Argan, "não é uma imagem que se liberta da matéria, é uma imagem que se imprime sobre ela num ato de força" (1998, p. 240). A matéria, através da rude ação da técnica, torna-se imagem; isso pode ocorrer não só na xilogravura, mas também na pintura, na escultura e, por que não dizer, na literatura.

As grossas camadas de tinta sobre a tela, a violência com que se utiliza a combinação de cores, a transformação de um bloco maciço em escultura tornam-se imagens; assim como na literatura de Arlt, a mesma rudeza da combinação das palavras entre si criam imagens que permeiam a imaginação do leitor. Imagens capazes de expressar e estabelecer a comunicação com o outro. As imagens visuais povoam a narrativa de Arlt $\mathrm{e}$, durante a leitura de seus romances, o leitor tende a levar em consideração o processo imagético que se estabelece pelo trabalho do escritor com as palavras. 
Roberto Arlt, ao escrever, parece imprimir no papel (na matéria) as palavras com violência e a cidade ficcional, geométrica e cromática, surge no texto como se através de um ato de força.

As cores na narrativa arltiana frequentemente assumem o mesmo papel das cores nas telas expressionistas. Arlt muitas vezes não só é contrário aos critérios de verossimilhança do imaginário popular e da própria associação tradicional de algumas cores na literatura, como a estrutura de sua paisagem urbana muitas vezes se perde na turbulência dos traços e na intensidade da gama cromática.

De acordo com Argan (1998), a atribuição do significado pela cor "implica um juízo, uma postura moral ou afetiva em relação ao objeto a que se aplica; como o juízo se apresenta à percepção juntamente com o objeto, ele se manifesta como deformação ou distorção do objeto" (p. 240). A deformação é traço constante do expressionismo, a "decomposição" da aparência "natural" aparece através de "pinceladas destacadas, nítidas, dispostas com certa ordem e ritmo, que dão a ideia de matéria concreta, da cor e construção material da imagem". (ARGAN, 1998, p. 232)

A deformação no expressionismo, na maioria das vezes, se apresenta com forte agressividade; não se trata somente de uma distorção ótica que irá decompor o "motivo", mas da determinação de fatores subjetivos e objetivos que sugerem a intenção do artista. Na prosa arltiana circula um grande número de deformes e a deformação, nesse caso, não é só física, é também psicológica, frequentemente o físico dos personagens é a expressão do interior. A natureza e a paisagem urbana também costumam expressar o estado anímico dos personagens, e o mundo inanimado também sofre mutilações, por exemplo, o Astrólogo, em Los siete locos, utiliza fantoches para representar os chefes da Sociedade Secreta que articula, e um deles apresenta deformação.

Assim como os bonecos, os homens também se rompem. Erdosain frequentemente blasfema contra "la puerca civilización" que "lo ha magullado, lo ha roto enternamente"; o protagonista confirma a decomposição de sua interioridade na seguinte passagem do texto:

\footnotetext{
- Padre, padre mío: estoy solo. He estado siempre solo. Sufriendo. ¿Qué tengo que hacer? Me han roto desde chico, padre. Desde que empecé a vivir. Siempre me han roto. A golpes, a humillaciones, a insultos. - No puedo más, ahora. Estoy por dentro magullado, roto, padre. Me han destrozado como a una res. Igual que en el matadero. (ARLT, 2000, p. 487)
}

A mutilação do corpo algumas vezes aparece no subconsciente como a imposição de um castigo e, de acordo com Gnutzmann (1984, p. 68), chega a seu clímax em duas alucinações de Erdosain, quando o personagem vê seu corpo sem cabeça, cravado no chão pelos pés, com uma engrenagem no pescoço que faz jorrar o sangue. $\mathrm{E}$ a visão de mutilações e desmembramento se repete durante a narrativa e "no se refieren tan solo a su propio cuerpo, sino que abarcan a la naturaleza y la humanidad en general." (GNUTZMANN, 1994, p. 69)

A deformação física também se apresenta através de comparações estabelecidas com criaturas não humanas. Em uma passagem do romance, Erdosain relaciona o nascimento de uma criança ao nascimento de um verme, que é amamentado por um 
monstro pálido e hediondo. Segundo o protagonista:

[...] a lo largo de todos los caminos del mundo hay casitas, chatas o con techos en declive, o con tejados a dos aguas, con empalizadas; y que en estas casas el gusano humano nace, lanza pequeños grititos, es amamantado por un monstruo pálido y hediondo, crece, aprende un idioma que otros tantos millones de gusanos ignoran, y finalmente es oprimido por su prójimo o esclaviza a los otros. (ARLT, 2000, p.470)

A maioria dos personagens arltianos sofre de alguma desfiguração, física ou psicológica, em menor ou maior grau. Como no quadro de Edvard Munch Skrik (O grito), a geometria da cidade arltiana se opõe à deformidade das figuras e a paisagem é tão angustiante quanto a figura em primeiro plano. A palavra, o grito, para Munch, é som inarticulado, instável, ambíguo, não é dotada de significado fixo, assim como a palavra para Arlt. Tanto o escritor como o pintor se evadem no símbolo e talvez seja essa ambiguidade, típica do movimento expressionista, que torna a obra inquietante e agressiva.

Outro pintor que retratou a paisagem urbana de maneira que se pode estabelecer alguns pontos de contato com a cidade ficcional de Arlt é seu conterrâneo Xul Solar. Oscar Agustín Alejandro Schulz Solari (1887-1963) é um importante representante da vanguarda na América Latina. O pintor viaja à Europa em 1903, lugar em que tem contato com as experiências e a linguagem da vanguarda, e regressa em 1924 a Buenos Aires, onde encontra uma cidade totalmente transformada daquela que deixou para trás quase vinte anos antes.

Xul Solar irá expressar as transformações ocorridas em Buenos Aires em sua produção artística e o que "se mescla en sus cuadros también se mezcla en la cultura de los intelectuales: modernidad europea y diferencia rioplatense, aceleración y angustia, tradicionalismo y espiritu renovador; criollismo y vanguardia" (SARLO, 1988, p. 15). A arquitetura das paisagens urbanas de Xul Solar se assemelha à dos grandes centros urbanos; o artista também conseguiu apreender na tela as tecnologias e maquinarias da modernidade. De acordo com Beatriz Sarlo, o pintor:

[...] deconstruye el espacio plástico, volviéndolo al mismo tiempo abstracto y tecnológico, geométrico y habitado por símbolos de una peculiar ficción mágico-científica. Los aviadores dibujados por Xul flotan en planos donde se mezclan banderas e insignias: una cita extremamente elaborada que pode leerse como la suma de modernización técnica y diversidad nacional de las que Buenos Aires se convierte en escena y soporte. (1990, p. 38)

Assim como a cidade de Arlt, a urbe de Xul Solar é formada por figuras geométricas superpostas, ruas e construções labirínticas, cilindros, ângulos agudos, linhas horizontais. Os habitantes da cidade também são formados por elementos geométricos onde círculos, retângulos e outros ângulos constituem cabeças e corpos. Essas características apagam, em alguns momentos, a noção de humanidade dos seres, assim como, em alguns desenhos, a presença de olhos e bocas nas construções em concreto remetem à metáfora biológica da cidade.

Supostamente Roberto Arlt e Xul Solar se interessavam pela combinação Bu-enos Aires /Modernidade e retrataram a cidade como lugar efetivo das mudanças. 
A heterogeneidade do ambiente e as invenções tecnológicas proporcionaram novas experiências de espaço e de tempo, a velocidade dos transportes, a iluminação, as cores da urbe, as grandes construções fechadas se opõem ferozmente à cidade não modernizada.

Beatriz Sarlo definiu a Buenos Aires moderna como uma "cidade de mescla". Segundo ela, o espaço assim definido é o cenário onde perseguimos os fantasmas da modernidade, "la ciudad es la más poderosa máquina simbólica del mundo moderno." (SARLO, 1990, p. 37), e Arlt e Xul perseguiram esses fantasmas e os reviveram em suas obras.

Acreditamos que nesta pesquisa foi possível constatar, nos textos de Roberto Arlt, especialmente em Los siete locos e Los lanzallamas, procedimentos de composição expressionista tais como: a deformidade, a exaltação da cor, a valorização do espaço, o ritmo, a sátira dos tipos sociais, a geometrização, a presença de elementos grotescos, entre outros.

A modernidade relacionada à urbanização como um processo caótico foi fundamental para a elaboração tanto da arte expressionista como para a produção literária arltiana. Arlt encontrou na Buenos Aires que se modernizava a matéria de sua escritura, assim como as transformações aceleradas da paisagem de Berlim inspiraram os artistas expressionistas e modificaram o teor de sua arte.

Segundo Viviana Gelado (2007, p. 107) na escrita arltiana não só encontramos características do expressionismo na descrição de exteriores da modernidade urbana, como também na criação de interiores opressivos e personagens aterrorizadoras. Assim como o expressionista norueguês Edvard Munch, Arlt conseguiu expressar as inquietações da alma.

Não se pode afirmar categoricamente que o texto de Arlt é um texto expressionista porque se o fizéssemos estaríamos reproduzindo o mesmo discurso que a crítica fez nos anos 20 e 30, quando denominou o díptico arltiano de realista, cômoda categoria classificatória. Entretanto, acredita-se que a cidade arltiana pode ser lida através de um olhar expressionista a partir do momento em que se estabelecem pontos de contato com a pintura expressionista e se leva em consideração a constituição dessa poética dentro do movimento do Die Brücke. Durante muito tempo, a crítica argentina categorizou os romances Los siete locos e Los lanzallamas como realismo de protesto, entretanto, é difícil imaginar que Arlt se conformasse com uma literatura meramente representativa, que refletisse o "real" e muito menos de protesto.

Concordamos com Maryse Renaud quando afirma que "es tan acusado el parentesco que guardan Los siete locos y Los lanzallamas con la sensibilidad expresionista y tan absorbente la escritura arltiana - sus detractores dirían confusa - que parece poco probable que tales similitudes sólo se deban a la casualidad". (2000, p. 695)

A geometrização incisiva do espaço nos romances, as cores nauseantes, a devastação do emocional, a angústia, o patético, o grotesco, a agressividade da paisagem, a presença de passagens altamente descritivas aproximam a cidade arltiana do expressionismo. O processo de modernização da cidade de Buenos Aires nos anos $20 \mathrm{e}$ 30 exigiu o nascimento de uma literatura que desse conta das transformações urbanas e aparentemente foi isso que Arlt tentou abarcar em seu díptico.

O diálogo entre o texto arltiano e o expressionismo alemão pode servir para aprofundar, desvendar e compreender o processo de construção da narrativa arltiana e 
a intensidade violenta e chocante de sua cidade ficcional. Arlt, Meidner, Kirchner, Grosz e Munch mostraram que é possível produzir arte sobre e desde uma perspectiva de fracasso e impotência.

\section{Referências bibliográficas}

ARLT, Roberto. Los siete locos - Los lanzallamas: edición crítica. 1. ed. Colección Archivos 44. Nanterre Cedex: 2000.

BEHR, Shulamith. Expressionismo; São Paulo: Cosac e Naify, 2000.

BARTHES, Roland. A aventura semiológica. Trad. Mário Laranjeira. São Paulo: Martins Fontes, 2001.

BENJAMIN, Walter. A modernidade e os modernos. Rio de Janeiro: Tempo Brasileiro, 2000 .

. Paris, capital do século XIX. A Paris do Segundo Império de Baudelaire. Parque Central. Teses sobre filosofia da história. In. KOTHE, Flávio R. (Org.). Walter Benjamin. São Paulo: Ática, 1985.

. Passagens; edição alemã de Rolf Tiedemann; organização da edição brasileira Willi Bolle; colaboração na organização da edição brasileira Olgária Chain Feres Matos; tradução do alemão Irene Aron; tradução do francês Cleonice Paes Barreto Mourão, Belo horizonte: Editora UFMG; São Paulo: Imprensa Oficial do Estado de São Paulo, 2007, $1^{\text {a }}$ reimpressão.

BERMAN, Marshall. Tudo que é sólido desmancha no ar: a aventura da modernidade. Trad. Carlos Felipe Moisés, Ana Maria L. Iorinatti. São Paulo: Cia. das Letras, 1986.

BRESCIANI, Stella Maria. (Org.) Palavras da Cidade. 1 ed. Porto Alegre: Ed. Universidade/UFRGS, 2001.

CARDINAL, Roger. O expressionismo. Rio de Janeiro: Zahar, 1988.

CRUZ, Cláudio Celso Alano da. Sobre alguns temas arrabaleros em Borges. In: Costa, Walter; Alcaraz, Rafael Camorlinga. (Orgs.). Hispanistas 2004 - Literatura Hispanoamericana. Florianópolis: UFSC/DLLE/ABH, 2006, v. 1.

PUCRS: IEL, 1994.

Literatura e cidade moderna: Porto Alegre 1935. Porto Alegre: EDI-

DAHER, Luiz Carlos. Arquitetura e expressionismo. Dissertação de Mestrado USP, Faculdade de Arquitetura e Urbanismo. São Paulo, 1979.

DIMAS, Antonio. Espaço e romance. 3. ed. São Paulo: Ática, 1994.

DUBE, Wolf-Dieter. O expressionismo. São Paulo: Verbo. Ed. USP, 1976.

FALK, Walter. Impresionismo y expresionismo: dolor y transformación en Rilke, Kafka, Trakl. Madrid: Guadarrama, 1963.

FOUCAULT, Michel. A arqueologia do saber. Rio de Janeiro: Forense Universitária, 1997. . Isto não é um cachimbo. Rio de Janeiro: Editora Paz e Terra S.A., 1988.

GELADO, Viviana. A poética expressionista na narrativa de Roberto Arlt. In. Fragmentos, número 32, p. 101/115, Florianópolis/ jan. - jun. / 2007. 
GNUTZMANN, Rita. Roberto Arlt o el arte del calidoscopio. Bilbao: Universidad del País Vasco, 1984.

GUERRERO, Diana. Arlt: el habitante solitario. 2. ed. Buenos Aires: Catálogos, 1986.

JITRIK, Noé. Un utópico país llamado Erar. In: Los siete locos - Los lanzallamas: edición crítica. 1. ed. Colección Archivos 44. Nanterre Cedex: 2000.

. (director). Historia critica de la literatura argentina. Buenos Aires, Emecé, 2006, v. V: La crisis de las formas, $1^{\text {a }}$. Edición.

. Historia critica de la literatura argentina. Buenos Aires, Emecé, 2004, v. 9: "El oficio se afirma", 1. ed.

. Historia critica de la literatura argentina. Buenos Aires, Emecé, 2002, v. 6: "El imperio realista", 1. ed.

JORDAN, Paul (Org.). Roberto Arlt. Florianópolis, Fragmentos, n. 32, 2007.

LYNTON, Norbert. Expressionismo. In: Conceitos da Arte Moderna. Rio de Janeiro: Zahar, 2000.

MASOTTA, Oscar. 1. ed. Sexo y traición en Roberto Arlt. Buenos Aires: Editorial Eterna Cadencia, 2008.

MORSE, Richard M. As cidades 'periféricas' como arenas culturais: Rússia, Áustria, América Latina. In: Estudos Históricos, Rio de Janeiro, v. 8, n. 16, 1995, p. 205-225.

NOGUÉS, Germinal. Buenos Aires, ciudad secreta. 2 ed. Buenos Aires: Editorial Sudamericana, 1996.

RAMA, Ángel. La ciudad letrada. Montevideo: Arca, 1998. . Transculturación narrativa en América Latina. México: Siglo XXI,

1987.

RENAUD, Maryse. Los siete locos y Los lanzallamas: audacia y candor de expresionismo. In: Los siete locos - Los lanzallamas: edición crítica. 1. ed. Colección Archivos 44. Nanterre Cedex: 2000.

. La ciudad babilônica o los entretelones Del mundo urbano en Los siete locos y los lanzallamas. In: CAMPRA, Rosalba. (coord.) La selva en el damero: espacio literario y espacio urbano en América Latina. Pisa: Giardini Editori, 1989.

RIVERA, Jorge. B. Textos sobre Roberto Arlt y la ciudad rabiosa. In: América latina: palavra, literatura e cultura, v. 2, São Paulo: Editora UNICAMP 1994.

SARLO, Beatriz. Una Modernidad Periférica: Buenos Aires 1920 y 1930. $1^{\mathrm{a}}$ ed. / 3. reimp. Nueva Visión, Buenos Aires: 2003.

Editores Argentina, 2007.

Escritos sobre literatura argentina. 1. ed. Buenos Aires: Siglo XXI, . Modernidad y mezcla cultural: el caso de Buenos Aires. In: Modernidade: Vanguardas Artísticas na América Latina. Ana Maria de Moraes Belluzzo, organizadora; colaboradores Aracy Amaral... (et al.) São Paulo: Memorial: UNESP, 1990.

. Arlt: cidade real, cidade imaginária, cidade reformada. In: Chiappini,

L. \& Aguiar, Flávio W. de (Orgs). Literatura e História na América Latina: Seminário Internacional, 9 a 13 de setembro de 1991. Sao Paulo: EDUSP, 1993, p. 223-242.

SIMMEL, Georg. et al. A metrópole e a vida mental. In: O fenômeno urbano. 4. ed. Rio de Janeiro: Zahar, 1979.

TORRE, Guilhermo. Historia de las literaturas de vanguardia. Porto: Gua- 


\section{outraTravessia}

darrama, 1972.

VIÑAS, David. Literatura Argentina y Política: de los jacobinos porteños a la bohemia anarquista. Buenos Aires: Sudamericana, 1995.

Américas, 1967.

"Prólogo" a Roberto ARTL. Antología. La Habana: Casa de las

ZUBIETA, Ana Maria. El discurso narrativo arltiano: intertextualidad, grotesco y utopía. 1. ed. Buenos Aires: Hachette, 1987. 